\title{
Does an additional UV LED improve the degree of conversion and Knoop Hardness of light-shade composite resins?
}

\author{
Maria Cecília Caldas Giorgi ${ }^{1}$ \\ Flávio Henrique Baggio Aguiar ${ }^{1}$ \\ Luís Eduardo Silva Soares ${ }^{2}$ \\ Airton Abrahão Martin² \\ Priscila Christiane Suzy Liporoni ${ }^{3}$ \\ Luís Alexandre Maffei Sartini Paulillo
}

\section{ABSTRACT}

Objective: The purpose of this study was to evaluate the degree of conversion (DC) using FTRaman spectroscopy and the Knoop hardness (KHN) of composites cured by second and third-generation LED light curing-units (LCU), Radii Cal and Ultralume 5.

Methods: Three composites (Filtek Supreme XT, Filtek Z350, and Esthet X) were selected for this study. KHN testing ( $\mathrm{n}=10)$ was performed with 10 indentations for the top (T) and bottom (B) surfaces. For $D C(n=10)$, both the T and B surfaces were analyzed.

Results: For KHN, the three composites differed in hardens. There was a "LCU-surface" interaction, in which Radii Cal showed significantly greater hardens in the B surface. For DC, there was a "composite-surface-LCU" interaction. For the "composite" factor, there was no significant difference between the groups, except for Supreme XT-Radii Cal (T or B surfaces). For the "LCU" factor there was a significant difference for Supreme XT T surface, Ultralume 5 obtained a higher DC. For the Z350 T surface, a significant difference in the DC in which Radii Cal obtained better results. For the "surface" factor, all groups presented T surfaces with a higher DC than the B surfaces, the sole exceptions involved Esthet X-Radii Cal and Z350-Ultralume 5.

Conclusion: Knowledge regarding composite composition and the characteristics of LCUs are important for effective polymerization. (Eur J Dent 2012;6:396-401)

Key words: Composite resin; UV LED; degree of conversion

1 Department of Restorative Dentistry, Piracicaba Dental School, State University of Campinas (UNICAMP), Piracicaba (SP), BRAZIL

2 Laboratory of Biomedical Vibrational Spectroscopy (LEVB), Research and Development Institute (IPD), Vale do Paraíba University (UNIVAP), São José dos Campos (SP), BRAZIL

3 Department of Restorative Dentistry, School of Dentistry, Taubaté University (UNITAU), Taubaté (SP), BRAZIL

- Corresponding author: Dr. Flávio Henrique Baggio Aguiar Department of Restorative Dentistry, Piracicaba Dental School, State University of Campinas (UNICAMP), Piracicaba (SP), BRAZIL

Tel: +55 1921065337 Email: aguiar@fop.unicamp.br

\section{INTRODUCTION}

Since light-cured composite resins have become an integral part of modern dentistry, polymerization lamps have become a key instrument in dental practice. ${ }^{1}$ Both the light source and the resin composite play an important role in ensuring adequate polymerization. Until the development of light-emitting diode (LED) curing units, the commonly used LCUs for almost 40 years were the quartz-tungsten-halogen (QTH) LCUs. ${ }^{2,3}$ The advantages of LED LCUs include the narrow spectral emission of gallium nitride blue LEDs. This emission spectrum is centered at $470 \mathrm{~nm}$ and covers 
the absorption of camphorquinone (CQ), the most common photoinitiator used in dental composites. Thus, no filters are required in LED LCUs. Further, LED LCUs are less energy-consuming than QTH LCUs and have a lifetime of several thousand hours ${ }^{4}$ without a significant intensity loss.,

The introduction of LEDs LCUs occurred in 2000 and these have been subjected to three main changes in technology over the years. ${ }^{7}$ The first generation of LED LCUs usually contained multiple low power LEDs, however these lights presented low irradiance and were unable to cure resin composites as well as QTH LCUs.8,9 Secondgeneration LED LCUs used one high power LED to provide greater light output, but the spectral bandwidth remained narrower than that of QTH LCUs. ${ }^{9}$ This narrow spectrum is a problem for lighter composites that uses photoinitiators other than CQ, le.g, 1-phenyl-1,2-propanodione (PPD), bisacylphsphine oxide (BAPO), triacylphosphine oxides (TAPO)). For these composites, the absorption profile is shifted to the shorter wavelengths with maximum absorption centered at roughly $400 \mathrm{~nm},{ }^{10} 320 \mathrm{~nm},{ }^{10}$ and $390 \mathrm{~nm}^{11}$ respectively. Thirdgeneration LED LCUs use a combination of blue and ultraviolet LEDs to produce a broader spectral output, and these lights may polymerize a broader range of resins than the second-generation curing lights.

The aim of this study was to directly and indirectly evaluate the degree of conversion by means of FT-Raman Spectroscopy and Knoop Hardness testing of composites light-cured with $2^{\text {nd }}$ and $3^{\text {rd }}$ generation LED LCUs. The null hypotheses were: (1) use of $2^{\text {nd }}$ and $3^{\text {rd }}$-generation LED LCU does not affect the microhardness of composites; (2) use of $2^{\text {nd }}$ and $3^{\text {rd }}$-generation LED LCUs does not affect the degree of conversion of composites.

\section{MATERIAL AND METHODS}

Three commercial composites (Table 1) and two LED LCUs (Table 2) were selected for this study.

\section{Knoop Hardness Test}

Sixty cylindrical specimens were prepared in stainless steel molds $15 \mathrm{~mm}$ in diameter and $2 \mathrm{~mm}$ thick). A mylar strip was positioned on the bottom of the mold. The cavity was randomly filled in one increment and covered with another Mylar strip in order to provide a flat surface and the strip was

Table 1. Technical profile of composite resins evaluated in this study.

\begin{tabular}{|c|c|c|c|c|}
\hline Composite (manufacturer) & Color Lot & Organic Matrix* & Filler & Photoinitiator \\
\hline Filtek Supreme XT & $\begin{array}{c}\text { WE } \\
\text { Lot 8BY }\end{array}$ & $\begin{array}{l}\text { Bis-GMA } \\
\text { Bis-EMA6 }\end{array}$ & $\begin{array}{l}\text { non-agglomerated/non-aggre- } \\
\text { gated, } 20 \mathrm{~nm} \text { silica nanofiller and } \\
0.6-1.4 \mathrm{~nm} \text { agglomerated silica } \\
\text { nanocluster. } \quad 78.5 \mathrm{wt} . \%\end{array}$ & Unknown(§) \\
\hline $\begin{array}{l}\text { (3M ESPE Dental Products, St } \\
\text { Paul, MN, USA) }\end{array}$ & & $\begin{array}{l}\text { UDMA } \\
\text { TEGDMA }\end{array}$ & $58-60 \%$ by volume(§) & \\
\hline Filtek Z350 & $\begin{array}{c}\text { A1 } \\
\text { Lot } 7 C A\end{array}$ & $\begin{array}{l}\text { Bis-GMA } \\
\text { Bis-EMA6 }\end{array}$ & $\begin{array}{l}\text { non-agglomerated/non-aggre- } \\
\text { gated, } 20 \mathrm{~nm} \text { silica nanofiller and } \\
0.6-1.4 \mathrm{~nm} \text { agglomerated silica } \\
\text { nanocluster. } \quad 78.5 \mathrm{wt} . \%\end{array}$ & Unknown(§) \\
\hline $\begin{array}{l}\text { (3M ESPE Dental Products, St } \\
\text { Paul, MN, USA) }\end{array}$ & & $\begin{array}{l}\text { UDMA } \\
\text { TEGDMA }\end{array}$ & $58-60 \%$ by volume(§) & \\
\hline Esthet X & $\begin{array}{c}\text { WE } \\
\text { Lot } 0707000200\end{array}$ & $\begin{array}{l}\text { Bis-GMA } \\
\text { Bis-EMA }\end{array}$ & $\begin{array}{l}\text { barium fluoro alumino boro silicate } \\
\text { glass, with mean particle size be- } \\
\text { low } 1 \mu \mathrm{m} \text { and nanofiller silica par- } \\
\text { ticle size } 0.04 \mu \mathrm{m} 60 \% \text { by volume }\end{array}$ & Camphorquinone \\
\hline (Dentsply/Caulk Milford, DE) & & TEGDMA & & \\
\hline
\end{tabular}

Table 2. Technical details of Light-Curing Units used in this study

\begin{tabular}{|c|c|c|c|c|c|c|}
\hline \multirow[t]{2}{*}{ LCU (manufacturer) } & \multirow[t]{2}{*}{ Description } & \multicolumn{3}{|c|}{$\begin{array}{c}\text { Irradiance }\left(\mathrm{mW} / \mathrm{cm}^{2}\right) \\
\text { Density }\end{array}$} & \multirow{2}{*}{$\begin{array}{l}\text { Exposure } \\
\text { duration }\end{array}$} & \multirow{2}{*}{$\begin{array}{l}\text { Energy } \\
\text { Density } \\
\left(\mathrm{J} / \mathrm{cm}^{2}\right)\end{array}$} \\
\hline & & Total & $<440 \mathrm{~nm}$ & $450-490 \mathrm{~nm}$ & & \\
\hline $\begin{array}{l}\text { Radii Cal (SDI Limited, } \\
\text { Bayswater, Australia) }\end{array}$ & $\begin{array}{l}\text { Second-generation LED curing using one high power } \\
\text { LED, cordless, lithium battery operated }\end{array}$ & 1250 & 40 & 964 & $25 s$ & $\approx 25$ \\
\hline $\begin{array}{l}\text { UltraLume } 5 \text { (Ultradent, } \\
\text { South Jordan, USA) }\end{array}$ & $\begin{array}{l}\text { Third-generation LED curing using a combination of } \\
\text { five LEDs, hand-held wand, not battery operated }\end{array}$ & 780 & 89 & 520 & $20 \mathrm{~s}$ & 15,6 \\
\hline
\end{tabular}


covered with a glass plate. The sample was polymerized according to the six experimental groups $(n=10)$. Polymerization was performed with the light tip positioned $3 \mathrm{~mm}$ above the top surface of the sample. For Radii Cal, a 25 seconds exposure time was used since it was not possible exclude the 5 initial seconds in the exponential mode. Ultralume 5 required 20 seconds in the continuous mode. Immediately after, the hardness on the bottom and top of the specimen was tested using a Knoop hardness test (FM - Future Tech Corp., Japan) under a $10 \mathrm{~g}$ load for $10 \mathrm{~s}$. Ten measurements were taken for each surface, at the approximate center of the specimen. ${ }^{10}$ The values obtained were converted to Knoop Hardness Numbers (KHNs). The hardness ratio was calculated according to the formula:

Hardness Ratio= Hardness of bottom surface/ hardness of top surface

The data obtained from microhardness testing were submitted to an ANOVA with three factors (composite, LCU and surface - as repeated measures), and a Tukey test at the $a=.05$ significance level.

\section{FT-Raman Spectroscopy}

Each specimen $(n=10)$ was prepared with $160 \mathrm{mg}$ of uncured composite placed in a circular cavity $(7 \mathrm{~mm}$ in diameter $X 2 \mathrm{~mm}$ thick) centered in a stainless steel mold in the same manner as for Knoop hardness testing and the top and bottom surfaces were analyzed by FT-Raman spectroscopy. The spectra of uncured and cured resins were obtained by a FT-Raman spectrometer (RFS 100/S, Bruker Inc, Karlsruhe, Germanyl using 100 scans. The spectrum resolution was set to $4 \mathrm{~cm}^{-1}$. The samples were excited by the defocused line of an $\mathrm{Nd}$ :YAG laser source at $\lambda=1064 \mathrm{~nm}$ with a maximum laser power of approximately $100 \mathrm{~mW}$ at the sample.

The uncured composite $(n=3)$ was positioned on an aluminum rod in a sample holder mounted on an optical rail for spectrum collection. Three spectra were collected.

The average FT-Raman spectra were analyzed by selecting a range between 1590 and $1660 \mathrm{~cm}^{-1}$. A comparison of the height ratio of the aliphatic carbon-carbon double bond $(\mathrm{C}=\mathrm{C})$ at $1640 \mathrm{~cm}^{-1}$ with that of the aromatic component at $1610 \mathrm{~cm}^{-1}$ for the cured and uncured conditions was performed in order to estimate the DC using equation (1). The aromatic $\mathrm{C}=\mathrm{C}$ peak at $1610 \mathrm{~cm}^{-1}$ originated from the aromatic bonds of the benzene rings in the monomer molecules, and its intensity remained unchanged during the polymerization reaction. The percentage of DC was then calculated by:

DC $(\%)=100 *[1-$ Rcured/Runcured $]$ (1)

where $\mathrm{R}=$ band height at $1640 \mathrm{~cm}-1 /$ band height at $1610 \mathrm{~cm}^{-1}$. The $D C$ ratio was calculated using the formula:

Table 3. Mean of Knoop Hardness Number for composites and surfaces, compared by Tukey tests and Hardness Ratio (P>.05).

\begin{tabular}{lccl}
\hline Composite Resin & Light-Curing Unit & Top & Bottom \\
\hline \multirow{2}{*}{ Supreme XT } & Radii Cal & $41.41 \mathrm{Bb}$ & $44.98 \mathrm{Aa}$ \\
& Ultralume 5 & $40.2 \mathrm{Aa}$ & $39.01 \mathrm{Aa}$ \\
\hline \multirow{2}{*}{ Z350 } & Radii Cal & $34.9 \mathrm{Bb}$ & $39.29 \mathrm{Aa}$ \\
& Ultralume 5 & $35.49 \mathrm{Aa}$ & $35.15 \mathrm{Aa}$ \\
\hline \multirow{2}{*}{ Esthet X } & Radii Cal & $23.78 \mathrm{Bb}$ & $26.22 \mathrm{Aa} \bullet$ \\
& Ultralume 5 & $21.18 \mathrm{Aa}$ & $22.16 \mathrm{Aa} \bullet$ \\
\hline
\end{tabular}

Means followed by different letters and signs (upper case letters: row; lower case letters: column; signs: column) are significantly different.

Table 4. Mean and standard deviation (SD) of the DC $(\%)$ and $D C$ ratios $(P>05)$.

\begin{tabular}{|c|c|c|c|c|}
\hline \multirow[b]{2}{*}{ LCU } & \multirow[b]{2}{*}{ SURFACE } & \multicolumn{3}{|c|}{ COMPOSITE } \\
\hline & & ESTHET X & SUPREME XT & Z350 \\
\hline \multirow{3}{*}{ RADII CAL } & TOP & 63.87(2.08)Aa & $58.98(3.76) \mathrm{Ab}^{*}$ & 65.93(4.29)Aa \\
\hline & Воттом & 63.97(1.57)Aa & $56.52(2.77) \mathrm{Bb}$ & 62.02(3.65) Ba \\
\hline & ratio & 1.00 & 0.95 & 0.94 \\
\hline \multirow{3}{*}{ ULTRALUME 5} & TOP & 64.12(3.36)Aa & 63.49(4.94)Aa & $62.59(2.78) \mathrm{Aa}^{*}$ \\
\hline & Воттом & 61.83(3.20)Ba & $59.29(4.45) \mathrm{Ba}$ & 62.02(2.33)Aa \\
\hline & ratio & 0.96 & 0.93 & 0.99 \\
\hline
\end{tabular}

Means followed by different letters (upper case letters: column; lower case letters: row) are significantly different. (*) indicate statistically least DC when LCUs were compare. 
$D C$ Ratio= DC of bottom surface/DC of top surface

The data obtained in FT-Raman test were submitted to an ANOVA (factors: composite, LCU and surface), and Tukey test at the $\mathrm{a}=.05$ significance level.

\section{RESULTS}

Knoop Hardness test

The ANOVA showed a significant difference for each factor, as well as an interaction among the "LCU" and "surface" factors (Table 3). Composites resins were all significantly different from each other. For the LCU versus surface interaction, the highest hardness was obtained in the bottom for light curing with Radii Cal. This condition was significantly different from the others and no other differences were noted. The hardness ratio was > 0.9 in all groups.

\section{FT-Raman test}

There were significant differences between the factors "composite" and "surface" as well as a "composite versus surface versus LCU" interaction (Table 4). For the "composite" factor there was no significant difference between the groups, with the exception of Filtek Supreme XT lightcured by Radii Cal on either the top or bottom surfaces. For the "LCU" factor, there was a significant difference for the Supreme XT top surface, for which the $3^{\text {rd }}$ generation LED LCU obtained a higher DC. For the Z350 top surface, a significant difference in the DC was also noticed; Radii Cal obtained better results than Ultralume 5. For the "surface" factor, most groups presented top surfaces with higher degrees of conversion than the bottom surfaces; the only exceptions to this rule were for Esthet $X$ lightcured by Radii Cal and Filtek Z350 light-cured by Ultralume 5. The degree of conversion ratio was $>0.9$ for all experimental conditions.

\section{DISCUSSION}

The degree of conversion is related to the performance of resin-based dental materials. When higher degrees of conversion are obtained, improved mechanical properties are also achieved. ${ }^{12,13}$ Hardness is a parameter that has relevance for the behavior of composite resin restorations in the oral environment. ${ }^{14}$ In this study, curing effectiveness was measured using direct and indirect methods by means of FT-Raman Spectroscopy and Knoop Hardness respectively.

The hardness of composite resin is influenced by the composition of the resin matrix, filler type and filler load. ${ }^{4}$ According to material's profile, Filtek Supreme XT and Filtek Z350 have the same composition lalthough the percentage of monomeric components was not mentioned). For this study, these composites were selected in different shades since Z350 is not available in the WE shade. Different shades probably produce differences in translucency, opacity, and the type and content of pigment. These can control the transmittance spectrum of each shade of each material ${ }^{15}$ and may explain the higher KHNs obtained by the Filtek Supreme XT samples.

The microhybrid composite Esthet $X$ had the lowest hardness value (Table 3). This finding can be explained by composite composition, especially by the filler load and content. Esthet $X$ presented an irregular filler made of barium fluoro alumino boro silicate glass with a mean particle size below $1 \mu \mathrm{m}$ and nanofiller silica size of $0.04 \mu \mathrm{m}$. Filtek Supreme XT and Filtek Z350 presented $0.02 \mu \mathrm{m}$ nanosilica filler and loosely bound agglomerated zirconia/silica filler particles with a size of $5-20 \mathrm{~nm}$. The cluster particle size ranged from 0.6 to $1.4 \mu \mathrm{m}$ (Table 1). These are classified as nanocomposites; due the reduced dimensions of the particles and the presence of a wide size distribution, these composites showed increased filler load, reduced polymerization shrinkage and improved mechanical properties (e.g., increased microhardness ${ }^{16}$ ).

Higher KHNs were obtained using Radii Cal on the bottom surface, this difference was significant compared to the others conditions, and no further differences were noted (Table 3). Two possibilities may explain these results. First, the samples were prepared in one increment and were compressed so as to extrude excess material and obtain a flat surface. This could allow the resin matrix to accumulate at the top and condensate the filler at the bottom, thereby decreasing the hardness value of the top surface. Second, due to the difference in irradiance, light may have reached the bottom surface differently. 917 Radii Cal delivered radiant exposure above $25 \mathrm{~J} / \mathrm{cm}^{2}$ whereas Ultralume 5 delivered $15.6 \mathrm{~J} / \mathrm{cm}^{2}$.

For the Ultralume 5, no difference was observed. We thus conclude that the lowest radiant 
exposure received by the composite was not sufficient to cause this behavior. According to the scientific literature, a bottom-to-top surface hardness ratio $>0.8$ is defined as sufficiently cured ${ }^{14,18}$ For this study, all experimental groups were within this parameter.

Related to the DC, there were no statistically differences among the groups for either the top or bottom surfaces, the exception to this trend involved Filtek Supreme XT light-cured by $2^{\text {nd }}$ generation LED LCU (Table 4). This result may be because this particular composite and shade may contain photoinitiators in addition to $\mathrm{CQ}$. It may thus not have been completely excited by the narrow emission spectrum of Radii Cal. CQ is yellow, ${ }^{9}$ which makes it difficult to produce translucent or light shades and co-initiators are used to avoid this concern. Further, associations between $C Q$ and PPD have been shown to improve the $D C^{1}$; this results in lower quantities of $C Q$ being used in some composites formulations. ${ }^{2}$ The $3^{\text {rd }}$-generation LED LCU presented a broader emission spectrum, and these additional lower wavelengths had an effect on the polymerization of the Filtek Supreme XT composite. ${ }^{9}$ Thus, in agreement with several studies, we found that the effectiveness of curing associated with LED LCUs was material-dependent. 2,9,19

For the "LCU" factor, two experimental conditions showed significant differences in the DC. The first experimental condition was the top surface of Filtek Supreme XT, which showed a lower DC when light-cured by $2^{\text {nd }}$-generation LED LCUs than when light-cured by $3^{\text {rd }}$-generation LED LCUs. This difference can also be explained by the overlap of the emission spectrum of LCU and emission absorption of the composite resin, as mentioned before. For the bottom surface of Supreme XT, this effect was not observed because resin composites filter shorter light wavelengths more than longer ones. Therefore, the shorter wavelengths delivered by $3^{\text {rd }}$-generation LED LCUs may not reach the bottom of $2 \mathrm{~mm}$ thick specimens. 9.15 The second experimental condition in which a difference was noted was top surface of Z350 lightcured by Ultralume 5, which showed a significant lower DC than when this surface was light-cured by Radii Cal. This composite, selected in the A1 shade, probably has a higher content of $C Q$ and thus favors excitement by wavelengths above $440 \mathrm{~nm}$ (these wavelengths are more prevalent in $2^{\text {nd }}$-generation LED LCUs) (Table 2).
For the "surface" factor, the top surface of all samples presented an equal or higher DC than the bottom surface (Table 4). However, top surface is not an adequate clinical indicator of an adequately polymerized composite restoration, since even a poor light source may produce a well-cured surface that conceals inadequate or unpolymerized resin in deeper parts of the cavity. ${ }^{20}$ The conversion ratio (DC of bottom surface/DC of top surface) should be greater than 0.8 and thus the polymerization gradient should thus not exceed 0.1 to $0.2 .{ }^{21}$ The conversion ratio obtained in this study was found to be greater than 0.9 for all experimental conditions (Table 4).

\section{CONCLUSIONS}

The results of the present study require rejection of the first and second hypothesis, since $2^{\text {nd }}$ and $3^{\text {rd }}$-generation LED LCUs provide different levels of microhardness and degrees of conversion. The additional UV LED does not improve the DC or KHN at bottom surface of the studied composites.

\section{REFERENCES}

1. Jimenez-Planas A, Martin J, Abalos C, Llamas R. Developments in polymerization lamps. Quintessence Int 2008;39:e74-84.

2. Polydorou O, Manolakis A, Hellwig E, Hahn P. Evaluation of the curing depth of two translucent composite materials using a halogen and two LED curing units. Clin Oral Investig $2008 ; 12: 45-51$

3. Cavalcante LM, Valentino TA, Carlini B, Jr., Silikas N, Pimenta LA. Influence of different exposure time required to stabilize hardness values of composite resin restorations. $J$ Contemp Dent Pract 2009;10:42-50.

4. Ruttermann S, Tomruk S, Raab WH, Janda R. Effect of Energy Density on the Physical Properties of Resin-Based Restorative Materials when Polymerized with Quartz-Tungsten Halogen or LED-Light. Eur J Dent 2010;4:183-191.

5. Ceballos L, Fuentes MV, Tafalla H, Martinez A, Flores J, Rodriguez J. Curing effectiveness of resin composites at different exposure times using LED and halogen units. Med Oral Patol Oral Cir Bucal 2009;14:E51-56.

6. Beriat NC, Ertan AA, Canay S, Gurpinar A, Onur MA. Effect of different polymerization methods on the cytotoxicity of dental composites. Eur J Dent 2010;4:287-292.

7. Kramer N, Lohbauer U, Garcia-Godoy F, Frankenberger R. Light curing of resin-based composites in the LED era. Am J Dent 2008;21:135-142. 
8. Antonson SA, Antonson DE, Hardigan PC. Should my new curing light be an LED? Oper Dent 2008;33:400-407.

9. Price RB, Felix CA, Andreou P. Third-generation vs a second-generation LED curing light: effect on Knoop microhardness. Compend Contin Educ Dent 2006;27:490-496; quiz 497, 518.

10. Hammesfahr PD, O'Connor MT, Wang X. Light-curing technology: past, present, and future. Compend Contin Educ Dent 2002;23:18-24.

11. Burgess JO, DeGoes M, Walker R, Ripps AH. An evaluation of four light-curing units comparing soft and hard curing. Pract Periodontics Aesthet Dent 1999;11:125-132; quiz 134.

12. Price RB, Derand T, Loney RW, Andreou P. Effect of light source and specimen thickness on the surface hardness of resin composite. Am J Dent 2002;15:47-53.

13. Cassoni A, Ferla Jde O, Shibli JA, Kawano Y. Knoop microhardness and FT-Raman spectroscopic evaluation of a resin-based dental material light-cured by an argon ion laser and halogen lamp: an in vitro study. Photomed Laser Surg 2008;26:531-539.

14. Yazici AR, Kugel G, Gul G. The Knoop hardness of a composite resin polymerized with different curing lights and different modes. $J$ Contemp Dent Pract 2007;8:52-59.

15. Arikawa H, Fujii K, Kanie T, Inoue K. Light transmittance characteristics of light-cured composite resins. Dent Mater 1998;14:405-411.

16. Beun S, Glorieux T, Devaux J, Vreven J, Leloup G. Characterization of nanofilled compared to universal and microfilled composites. Dent Mater 2007;23:51-59.

17. Fan PL, Stanford CM, Stanford WB, Leung R, Stanford JW. Effects of backing reflectance and mold size on polymerization of photo-activated composite resin. J Dent Res 1984;63:1245-1247.

18. Schattenberg A, Lichtenberg D, Stender E, Willershausen B, Ernst CP. Minimal exposure time of different LED-curing devices. Dent Mater 2008;24:1043-1049.

19. El-Mowafy O, El-Badrawy W, Wasef M, Omar H, Kermanshahi S. Efficacy of new LED light-curing units in hardening of Class II composite restorations. J Can Dent Assoc 2007;73:253.

20. Soh MS, Yap AU, Yu T, Shen ZX. Analysis of the degree of conversion of LED and halogen lights using micro-Raman spectroscopy. Oper Dent 2004;29:571-577.

21. Pilo R, Cardash HS. Post-irradiation polymerization of different anterior and posterior visible light-activated resin composites. Dent Mater 1992;8:299-304. 